\title{
The Telomeric dG(GT) ${ }_{4} \mathrm{G}$ Sequence Can Adopt a Parallel-Stranded Double Helical Conformation
}

\author{
Anna K. Shchyolkina, Olga F. Borisova, Michael A. Livshits, Reinhard \\ Klement \& Thomas M. Jovin
}

To cite this article: Anna K. Shchyolkina, Olga F. Borisova, Michael A. Livshits, Reinhard Klement \& Thomas M. Jovin (2001) The Telomeric dG(GT) ${ }_{4}$ G Sequence Can Adopt a ParallelStranded Double Helical Conformation, Journal of Biomolecular Structure and Dynamics, 18:4, 493-503, DOI: 10.1080/07391102.2001.10506683

To link to this article: http://dx.doi.org/10.1080/07391102.2001.10506683

曲 Published online: 15 May 2012.

Submit your article to this journal $\widetilde{x}$

Џ Article views: 6

Q View related articles ¿

4 Citing articles: 1 View citing articles $\asymp$ 


\section{The Telomeric dG(GT) ${ }_{4} \mathbf{G}$ Sequence Can Adopt a Parallel-Stranded Double Helical Conformation}

\author{
http://www.adeninepress.com
}

\begin{abstract}
Oligonucleotides 3'-d(GTGTGTGTGG)-L-d(GGTGTGTGTG)-3' (hp-GT) and $3^{\prime}-$ d(G45TG4STG4STG4STGG)-L-d(GGTGTGTGTG)-3' (hp-SGT), $\left(\mathrm{L}=\left(\mathrm{CH}_{2} \mathrm{CH}_{2} \mathrm{O}\right)_{3}\right)$, were shown by use of several optical techniques to form a novel parallel-stranded (ps) intramolecular double helix with purine-purine and pyrimidine-pyrimidine base pairing. The rotational relaxation time of hp-GT was similar to that of a 10-bp reference duplex, and the fraction of unpaired bases was determined to be $\sim 7 \%$, testifying to the formation of an intramolecular double helical hairpin by the sequence under the given experimental conditions. A quasi-twostate mode of ps-double helix formation was validated, yielding a helix-coil transition enthalpy of $-135 \pm 5 \mathrm{~kJ} / \mathrm{mol}$. The $\mathrm{G} \cdot \mathrm{G}$ and $\mathrm{T} \cdot \mathrm{T}$ ( or ${ }^{4 \mathrm{ST}} \cdot \mathrm{T}$ ) base pair configurations and conformational parameters of the double helix were derived with molecular modeling by force field techniques. Repetitive $\mathrm{d}(\mathrm{GT})$ sequences are abundant in telomers of different genomes and in the regulatory regions of genes. Thus, the observed conformational potential of the repetitive $\mathrm{d}(\mathrm{GT})$ sequence may be of importance in the regulation of cell processes.
\end{abstract}

\section{Introduction}

Simple dinucleotide repeats abundant in a number of genomes (1) and capable of adopting unusual DNA structures have been shown to be important for basic genetic processes (2). For example, expansion of the GT dinucleotide repeat lead to blockage of strand exchange through enhanced binding to the RecA protein, thereby promoting crossing-over events between such repeats $(3,4)$.

In vertebrates, yeast, as well as many other eukaryotes, telomeres comprise TG/CA repeated sequences within the TG-containing $3^{\prime}$-end of chromosomes. The doublestranded regions of Saccharomyces cerevisiae telomeric DNA consists of $\sim 300 \mathrm{bp}$ of the $\mathrm{G}_{2-3}(\mathrm{TG})_{1-6} \mathrm{~T}$ sequence (5). It has been reported that the telomeres of yeast end in single-stranded GT overhangs (6), which are able to form G4 structures promoted by the RAP1 telomere-binding protein (7). The protein regulating the telomeric length, Tel2p, binds specifically to single-stranded $\mathrm{G}_{2-3}(\mathrm{TG})_{1-6} \mathrm{~T}$ overhang and promotes the formation of some secondary structures stabilized by G-G base pairs (8). Structure formation is mediated by protein interaction with the core $5^{\prime}$-GGTGTG-3' sequence. However, the exact nature of the underlying structure could not be determined in the cited study. Although no in vivo evidence exists for the presence of DNA quadruplexes in telomeres, various telomere-associated proteins recognize quadruplexes in vitro (9). Using the model oligonucleotides $3^{\prime}-\mathrm{d}(\mathrm{GT})_{5}{ }^{-}$ $\left(\mathrm{CH}_{2} \mathrm{CH}_{2} \mathrm{O}\right)_{3}-\mathrm{d}(\mathrm{GT})_{5}-^{-3^{\prime}}$ (parGT) and $5^{\prime}-\mathrm{d}(\mathrm{GT})_{5}-\left(\mathrm{CH}_{2} \mathrm{CH}_{2} \mathrm{O}\right)_{3}-\mathrm{d}(\mathrm{GT})_{5}-^{\prime}{ }^{\prime}$ (antiGT) in $\mathrm{NaCl}$ solutions, the formation of parallel-stranded rather than antiparallel-stranded GT quadruplexes was inferred (10). The repetitive GT-containing telomeric sequences from $S$. serevisiae 5'-AATTCTGGGTGTGTGGGTGTGTGGGTGTGTGGGTGTGG-3' form parallel-stranded G-quadruplexes, in contrast to the

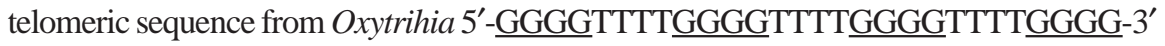

\author{
Anna K. Shchyolkina, 1* \\ Olga F. Borisova, ${ }^{1}$ \\ Michael A. Livshits, ${ }^{1}$ \\ Reinhard Klement ${ }^{2}$ \\ and Thomas M. Jovin ${ }^{2}$ \\ ${ }^{1}$ Engelhardt Institute of Molecular Biology, \\ Russian Academy of Sciences, \\ 117984 Moscow, Russia \\ 2Department of Molecular Biology, \\ Max Planck Institute for \\ Biophysical Chemistry, \\ D-37070 Göttingen, Germany
}

*Phone: (007) (095) 135 9789;

Fax: (007) (095) 135 1405:

E-mail: annas@genome.eimb.relarn.ru 
that form antiparallel-stranded G-quadruplexes (11). Recently a new structural mode - an end t-loop - was revealed in mammalian telomeres (12). These and other data suggest that peculiarities of telomeric repeating sequences may be the principal determinants for protein-assisted DNA structure formation at the ends of chromosomes.

In the present work we have demonsrated that in the oligonucleotide $3^{\prime}$-d(GTGTGTGTGG)-L-d(GGTGTGTGTG)-3', the repetitive $(\mathrm{GT})_{4}$ sequence flanked by guanines forms a parallel-stranded double helix with G.G and T.T base pairs. The thermodynamics and conformational features of the novel double helix were examined.

\section{Materials and Methods}

Oligonucleotides 3'-d(GTGTGTGTGG)-L-d(GGTGTGTGTG)-3' (hp-GT) and 3'd(G $\left.{ }^{4 S T G}{ }^{4 S T G}{ }^{4 S T G}{ }^{4 S T G G)-L-d(G G T G T G T G T G)-3 ' ~(h p-S G T), ~(L=~}\left(\mathrm{CH}_{2} \mathrm{CH}_{2} \mathrm{O}\right)_{3}\right)$, were synthesized by Syntol (Moscow). ${ }^{4 S T}$ nucleotides were introduced in the hpSGT in order to probe the specific conformations of thymines with optical techniques. Oligonucleotides were purified in gel and desalted. Samples contained 0.1 $\mathrm{M} \mathrm{NaCl}, \mathrm{LiCl}$ or $5 \mathrm{mM} \mathrm{MgCl} 2$ in the presence of $10 \mathrm{mM} \mathrm{Na}$-phosphate buffer, $\mathrm{pH}$ 7.4. The DNA concentrations are given in nucleotide units.

\section{Fluorescence Measurements}

The emission spectra of ethidium bromide $(\mathrm{EtBr})$ were measured with a Photon Technology Instruments spectrofluorimeter in thermostated cells at $3-4^{\circ} \mathrm{C}$. The fluorescence lifetimes of the dye and its DNA complexes were determined by the phase fluorimetry (10). For EtBr fluorescence the excitation wavelength was 365 or $546 \mathrm{~nm}$ and the emission wavelengths $>600 \mathrm{~nm}$. The data for the two excitation wavelengths were averaged.

The polarization of the fluorescence emission of intercalated $\operatorname{EtBr}(P)$ excited by vertically polarized light was determined by the equation

$$
P=\frac{I_{I I}-I_{\perp}}{I_{I I}+I_{\perp}}
$$

where $I_{I I}$ and $I_{\perp}$ are the parallel and perpendicular emission components, respectively. The relative dye concentration did not exceed 1 per 100 nucleotides, thereby avoiding depolarization due to energy transfer. Under the given experimental conditions, the added EtBr was essentially fully bound to the oligonucleotides, insuring that the contribution to the fluorescence signal of the free dye (the quantum yield of which is very low) was negligible. The rotational relaxation time, $\rho$, of EtBr bound to the oligonucleotides was estimated using the Perrin-Weber equation for a sphere or an ellipsoid of low asymmetry (13):

$$
\rho=3 \tau \frac{\left(1 / P_{0}-1 / 3\right)}{\left(1 / P-1 / P_{0}\right)}
$$

where $\tau$ is the measured fluorescence lifetime of bound $\mathrm{EtBr}$ at $3.5^{\circ} \mathrm{C}, P$ the measured polarization, and $P_{0}=0.42$ (14) the limiting polarization at infinite viscosity $(T / \eta \rightarrow 0)$, where $\eta$ is the viscosity of the solution and $T$ the absolute temperature.

The Fraction of Unpaired Bases, 1- $\theta$, of an oligonucleotide duplex structure was determined by a fluorescence technique developed previously and based on the measurements of the heterogeneous fluorescence lifetimes, $\tau$, of acridine orangeDNA complexes $(10,14)$. The fraction of unpaired bases was calculated from the equation 


$$
(1-\theta)=\left(1-\theta_{s t}\right) \cdot \frac{\left(\tau_{r}-\tau_{g}\right)}{\left(\tau_{r}-\tau_{g}\right)_{s t}}
$$

in which $\tau_{\mathrm{g}}$ and $\tau_{r}$ are the heterogeneous fluorescence lifetimes measured in the green $(\lambda<530 \mathrm{~nm})$ and red $(\lambda>600 \mathrm{~nm})$ spectral ranges, and parameters with the index st refer to a standard nucleic acid with a known fraction of unpaired bases under the conditions used: yeast tRNA ${ }^{\text {Phe }}\left(1-\theta_{\mathrm{st}}\right)=0.26 \pm 0.01$ in sodium salt solutions (15). For DNA the technique was validated using the oligonucleotide with telomeric sequence $\mathrm{d}\left(\mathrm{T}_{2} \mathrm{AG}_{3}\right)_{4}$ as a test. This oligonucleotide was shown to selffold giving a tetraplex structure with $(1-\theta)=0.25(16)$. The $1-\theta$ obtained with the AO lifetime technique appeared to be in a good agreement with this value. The excitation wavelength was $436 \mathrm{~nm}$. The oligonucleotide concentration was $20 \mu \mathrm{M}$, and $\mathrm{AO}$ was $10 \mu \mathrm{M}$. The accuracy of the technique has been shown to be $\sim 2 \%(10)$.

\section{Thermal Denaturation}

Melting curves were acquired with Jasco V-550 and Uvikon 943 (Kontron Instruments) spectrophotometers at 260 or $335 \mathrm{~nm}$ at discrete intervals advanced by $0.5^{\circ} \mathrm{min}^{-1}$. The samples contained specified concentrations of counterions in the presence of $10 \mathrm{mM}$ Na phosphate buffer, $\mathrm{pH}$ 7.4.

\section{Theoretical Description of the Helix-Coil Transition}

The melting of the hairpins was described with all-or-none model, i.e. the temperature dependent equilibrium between only two states - fully base paired and fully melted (17). The adequacy of the two-state model was confirmed by applying a zipper model with adjustable helix initiation factor $(14,18)$. The fitting procedure has given fairly small values of initiation factor $\left(\sim 10^{-4}-10^{-6}\right)$ and the transition enthalpy, and entropy values very close to those obtained with the two-state model.

Circular Dichroism (CD) measurements were carried out with J-720 and J-715 CD spectrometers (Jasco) in thermostatted cells. The spectra were obtained with a $1 \mathrm{~nm}$ bandwidth and $0.2 \mathrm{~nm}$ spectral resolution; three sequential scans were averaged.

\section{Molecular Modeling}

The double stranded part of the oligonucleotide 3'-d(GTGTGTGTGG)-L-(GGTGTGTGTG) -3' was modeled with the program NAMOT2 (19) as a 10 base pair parallel-stranded helix; i. e, the linker segment was omitted. A total of 81 start structures were generated by systematically changing the helical twist and rise. All structures were minimized with the AMBER V5.0 (20) package to an rms of 0.01 ( $\varepsilon=4$, Coulomb cutoff $25 \AA$ ). Color images were generated with VMD (21). The helical parameters given below were computed from the energetically most favorable structure out of the ensemble of 81 structures.

\section{Results and Discussion}

(A) Oligonucleotide 3'-d(GTGTGTGTGG)-L-d(GGTGTGTGTG)-3' Forms an Intramolecular ps Hairpin

\section{Spectra}

Measurements of circular dichroism taken at different temperatures showed formation of a structured conformation of the hp-GT oligonucleotide in $0.1 \mathrm{M} \mathrm{NaCl}$ at $0-5^{\circ} \mathrm{C}$ (Figure 1A). The presence of isodichroic points was consistent with the existence of only two forms in the samples: an ordered and a melted structure. The shape of the longwave positive band differed from that in the spectra typical for 
either antiparallel- or parallel-stranded quadruplexes of similar base content. The maximum was located at $272 \mathrm{~nm}$ whereas the positive CD maximum was located

\section{Shchyolkina et al.}

Figure 1: $\mathrm{CD}$ spectra of hp-GT and hp-SGT oligonucleotides. (A, B, C) $0.1 \mathrm{M} \mathrm{NaCl}$, Na phosphate buffer, pH 7.4. (A) hp-GT, temperature: $0^{\circ} \mathrm{C}$ (spectrum marked with $\mathrm{O}$ ), $5^{\circ} \mathrm{C}, 15^{\circ} \mathrm{C}, 20^{\circ} \mathrm{C}, 25^{\circ} \mathrm{C}$, $30^{\circ} \mathrm{C}, 40^{\circ} \mathrm{C}, 50^{\circ} \mathrm{C}$; (B) hp-SGT, temperature: $0^{\circ} \mathrm{C}$ (spectrum marked with $\mathrm{O}$ ), $5^{\circ} \mathrm{C}, 10^{\circ} \mathrm{C}, 15^{\circ} \mathrm{C}, 20^{\circ} \mathrm{C}$, $25^{\circ} \mathrm{C}, 30^{\circ} \mathrm{C}, 35^{\circ} \mathrm{C}, 40^{\circ} \mathrm{C}, 50^{\circ} \mathrm{C}, 60^{\circ} \mathrm{C}$; (C) $\mathrm{CD}$ spectra of hp-GT (O) and hp-SGT $(\bullet)$ at $0{ }^{\circ} \mathrm{C}$ and the difference CD(hp-SGT) minus CD(hp-GT) spectrum $(\Delta)$; (D) Comparison of CD spectra of hp-GT at $0^{\circ} \mathrm{C}$ in $5 \mathrm{mM} \mathrm{MgCl}_{2}(\mathrm{O})$ and in $0.1 \mathrm{M} \mathrm{NaCl}$, Na phosphate buffer, $\mathrm{pH} 7.4($ at $260 \mathrm{~nm}$ for the ps quadruplex, with all guanine in anti conformation, and at 295 $\mathrm{nm}$ for the antiparallel quadruplexes with two guanines in syn and two guanines in anti conformation $(11,22)$. Related temperature-dependent CD changes for the hp-SGT oligonucleotide are shown in Figure 1B. A comparison of the CD spectra for the two oligonucleotides at $0^{\circ} \mathrm{C}$ (Figure 1C) shows the presence of additional bands in the CD of hp-SGT (Figure 1C, the difference spectrum). The ${ }^{4 \mathrm{ST}}$-substitution of four thymines of hp-GT was selected for probing the structure because of its unique spectral properties, which allow a selective monitoring of the thymine conformations. The absorption maximum of $4 \mathrm{ST}$ included in an oligonucleotide lies at 320-357 nm, depending on the base context (23-25). The absorption band of $4 \mathrm{ST}$ in the hp-SGT is centered at 330-335 nm (not shown). The CD contribution of the modified base is of a "conservative" type: a positive band around $350 \mathrm{~nm}$ and a negative band around $285 \mathrm{~nm}$ with zero intersection point close to the $4 \mathrm{ST}$ absorption maximum (Figure 1C, difference spectrum). This finding leads to the conclusion that the observed difference between the hp-GT and hp-SGT CD spectra at $0^{\circ} \mathrm{C}$ can be attributed mainly to the optical $4 \mathrm{~S} \mathrm{~T}$ signal rather than to a marked conformational dissimilarity between the hp-GT and hp-SGT secondary structures. The $\mathrm{CD}$ band of $4 \mathrm{~S} \mathrm{~T}$ around $350 \mathrm{~nm}$ lies outside the spectral region for the other bases; thus, an increase in dichroism at this wavelength selectively monitors the involvement of this base in the formation of overall hp-SGT structure (Figure 1B).
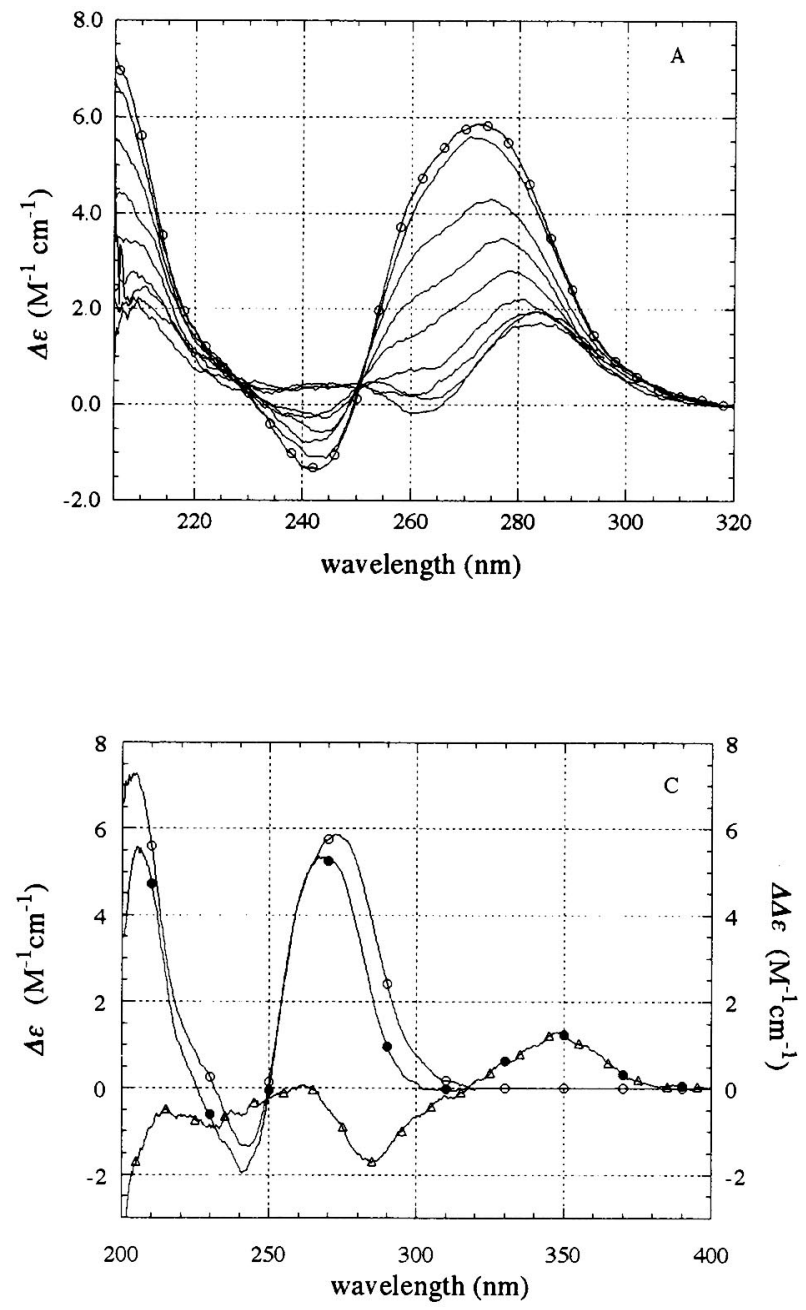
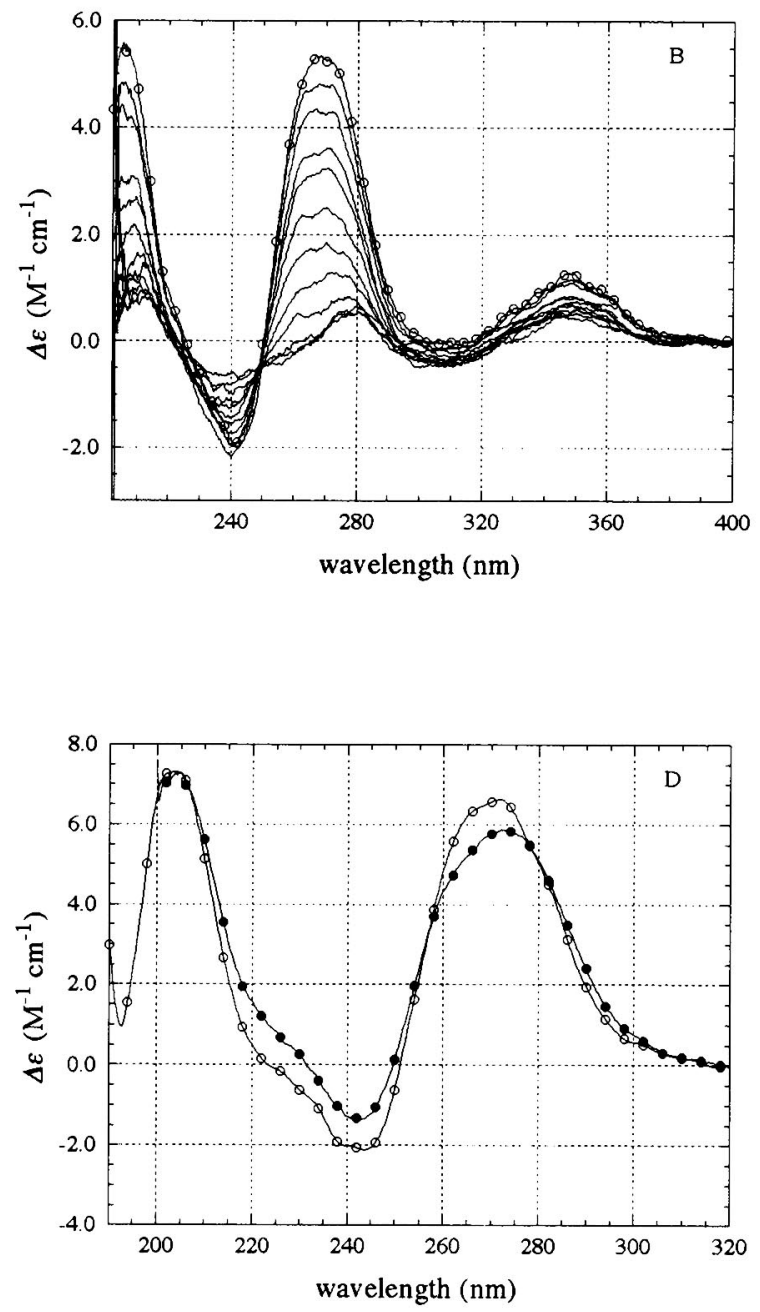
To specify whether the hp-GT structure was an intramolecular hairpin or was formed by two molecules, we determined its rotational relaxation time in comparison to that of a 10-bp duplex under the given experimental conditions. An EtBr probe was bound to the oligonucleotide and its rotational relaxation time $\rho$ was determined (Materials and Methods). The fluorescence lifetime of $\operatorname{EtBr}(\tau)$ bound to hp-GT was 16.5 \pm 1.0 ns at $3{ }^{\circ} \mathrm{C}$, that is 0.65 of the $26 \pm 1.0 \mathrm{~ns}$, lifetime characteristic of EtBr bound to DNA or to aps double-stranded oligonucleotides (14). For comparison, the $\tau$ of EtBr intercalated in ps hairpins with mixed AT and GC base pairs is $20-23 \pm 1.5 \mathrm{~ns}$ depending on the base sequence (14). We presume that the shorter fluorescence lifetime of the $\mathrm{EtBr}$ in the complex with the ps $\mathrm{dG}(\mathrm{GT})_{4} \mathrm{G}$ reflects an altered electronic environment of the dye positioned between the purine-purine and pyrimidine-pyrimidine base pairs. The polarization of the EtBr:hp-GT complex $\left(P_{h p-G T}\right)$ was $0.136 \pm 0.001$, while for several control ps and aps 10-bp hairpins the polarization $\left(P_{10 b p}\right)$ was 0.1 . The $\rho$ value for the intercalated EtBr:hp-GT complex ( $22.1 \mathrm{~ns}$ ) is very comparable to that for a EtBr complex with a 10-bp hairpin (22.6 ns), testifying to formation of an intramolecular hairpin structure by the hp-GT oligonucleotide. The $\rho$ value corresponded to a hairpin over a range of oligonucleotide concentrations from 10-100 $\mu \mathrm{M}$. Addition of $0.25 \mathrm{M} \mathrm{KCl}$ to the sample containing $0.1 \mathrm{M} \mathrm{NaCl}$ followed by heating the hp-GT sample and slow annealing to $3^{\circ} \mathrm{C}$ did not lead to an increase of the ratio of rotational relaxation times in Eq. 6. We note that the approach has been shown to be very sensitive to a presence of even minor admixtures of higher molecular weight species in a sample and as such is applicable for such poor intercalator-binding structures as G-quadruplexes $(10,26)$. The determination of molecularity of multistranded oligonucleotide complexes with the described $\mathrm{EtBr}$ probing has some advantages over that by the non-denaturing gel electrophoresis. In solution, the oligonucleotide species are studied under the equilibrium conditions, at the concentrations, temperatures and ionic conditions identical to those in the other physico-chemical studies. Unlike this, the conditions in gel are deviating from equilibrium, and moreover, oligonucleotides migration in a gel may disrupt weak multistranded complexes.

\section{The Fraction of Unpaired Bases}

The fraction of unpaired bases of the hp-GT at $3-4^{\circ} \mathrm{C}$ was determined from Eq. 3 : $(1-\theta)=0.07 \pm 0.03$. The value suggests that under the given conditions the hairpin on average has one broken base pair, presumably the one next to the non-nucleotide linker (for comparison, see 14). Examination of the hp-GT intramolecular structure supports the formation of a 10-bp double-helical hairpin with G.G and T.T pairs. An alternative hairpin structure produced by a sliding of the hairpin strands such as to allow the G.T pairing would lead to overhang of 2 unpaired Gs at the oligonucleotide ends, i.e. $20 \%$ of all bases. This alternative seems unlikely in view of the lower fraction of unpaired bases. The fact that the hp-GT oligonucleotide formed an intramolecular hairpin with $90 \%$ pairing was crucial for the determination of the mutual orientation of the strands, which was thus unequivocally parallel.

The $\mathrm{CD}$ spectrum of the ps $\mathrm{dG}(\mathrm{GT})_{4} \mathrm{G}$ hairpin provided insight into the handedness of the ps double helix. The CD spectra of hp-GT in $0.1 \mathrm{M} \mathrm{NaCl}$ and in $5 \mathrm{mM} \mathrm{MgCl}_{2}$ are shown in Figure 1D. They are indicative of a similar hp-GT conformation, though the somewhat enhanced dichroism in $\mathrm{MgCl}_{2}$ may have reflected the formation of a more ordered hairpin structure. The signs of the CD bands, and, particularly, the absence of a negative CD signal in the vacuum UV region (27), support the existence of a right-handed double helical conformation.

(B) Thermodynamic Parameters of ps 3'-d(GTGTGTGTGG)-L-d(GGTGTGTGTG)$3^{\prime}$ and $3^{\prime}-d\left(G^{4 S T G} G^{4 S T G} G^{4 S T G}{ }^{4 S} T G G\right)-L-d(G G T G T G T G T G)-3$ ' Hairpin Formation

Figure 2 shows UV melting curves at three different concentrations of the hp-GT 


\section{Shchyolkina et al.}
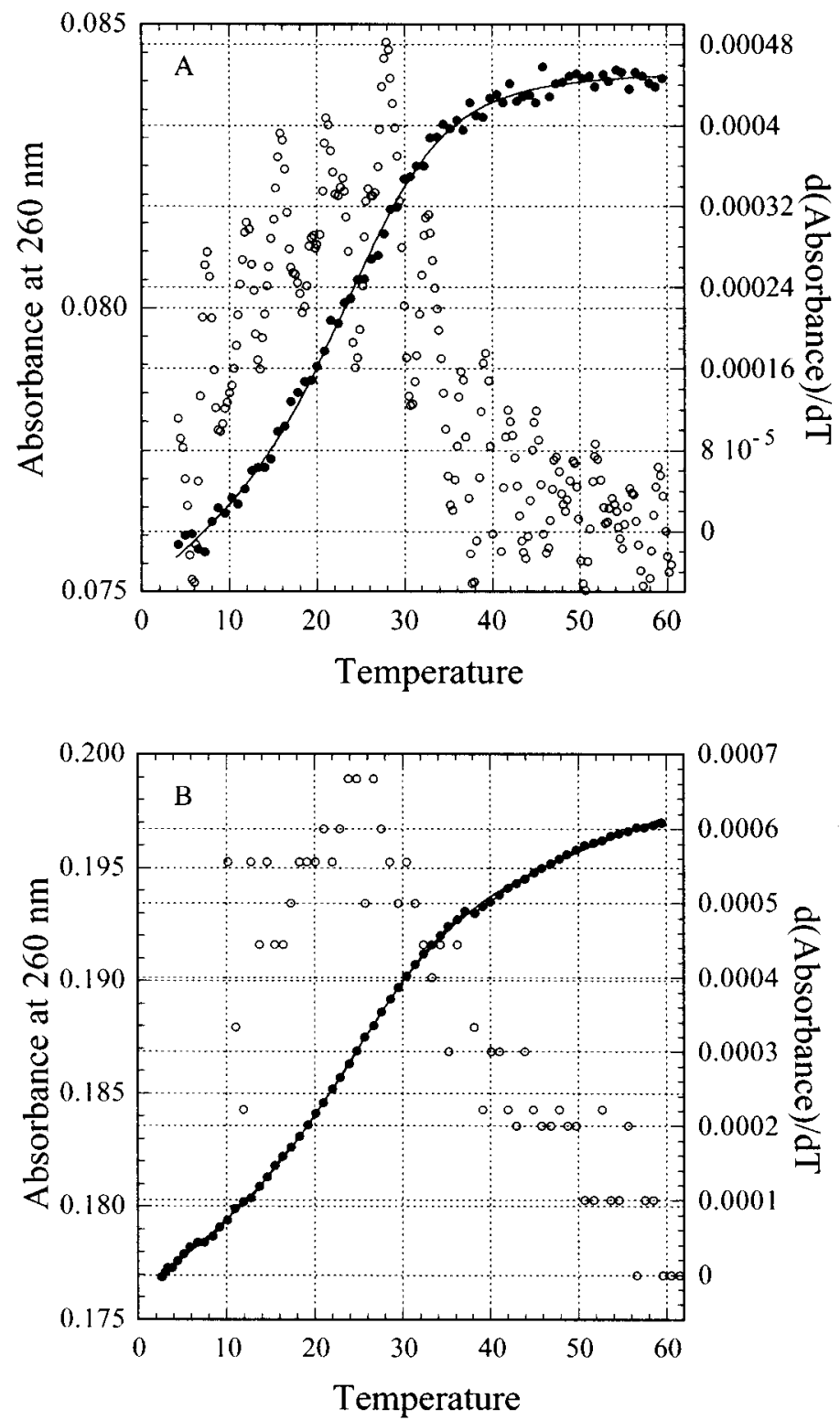

Figure 2: Thermal denaturation curves of the hp-GT hairpin at different oligonucleotide concentrations at $260 \mathrm{~nm}$. Each 3d or 4th experimental point is indicated; solid curves are the theoretical fits. (A) $0.47 \mu \mathrm{M}$, (B) $1 \mu \mathrm{M}$, (C) $2.5 \mu \mathrm{M}$. $0.1 \mathrm{M} \mathrm{NaCl}, 10 \mathrm{mM}$ Na phosphate buffer, $\mathrm{pH}$ 7.4. Left axis - absorbance

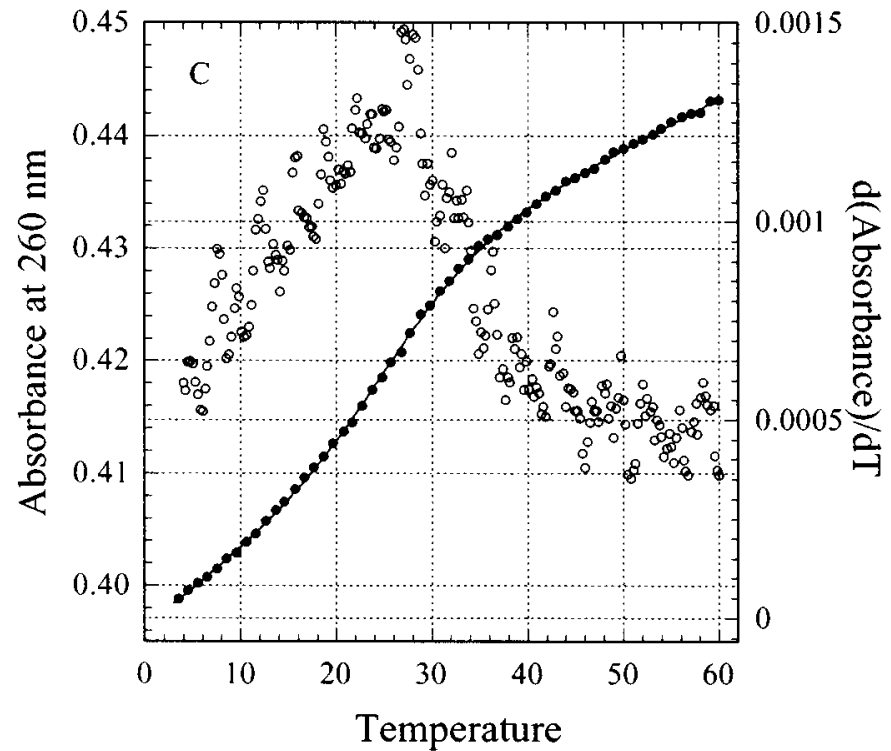


oligonucleotide $(0.5 \mu \mathrm{M}, 1 \mu \mathrm{M}$ and $2.5 \mu \mathrm{M})$ under the same salt condition $(0.1 \mathrm{M}$ $\mathrm{NaCl})$. The fact that the melting temperature $\left(26^{\circ} \mathrm{C}\right)$ did not depend on oligonucleotide concentration is convincing evidence for a unimolecular transition. The values for the thermodynamic parameters obtained by nonlinear fitting of the three curves to an all-or-none model of the transition were very similar. The transition enthalpy for hairpin formation was $\Delta \mathrm{H}=-135 \pm 5 \mathrm{~kJ} \mathrm{~mol}^{-1}$. The ${ }^{4} \mathrm{~S}$ modification of thymines (hp-SGT-oligonucleotide) did not lead to significant changes in the stability of the ps-hairpins (Figures 2 and 3A). Monitoring the absorbance of hp-SGT at $335 \mathrm{~nm}$ made it possible to follow the behavior of $4 \mathrm{ST} \cdot \mathrm{T}$ base pairs separately (Figure 3B). The data demonstrated clearly the simultaneous melting of $4 \mathrm{ST} \cdot \mathrm{T}$ and $\mathrm{G} \cdot \mathrm{G}$ base pairs. In addition, the ps double helix thermodynamic parameters computed from the melting profiles at $335 \mathrm{~nm}$ were quite similar to those obtained from melting at $260 \mathrm{~nm}$.
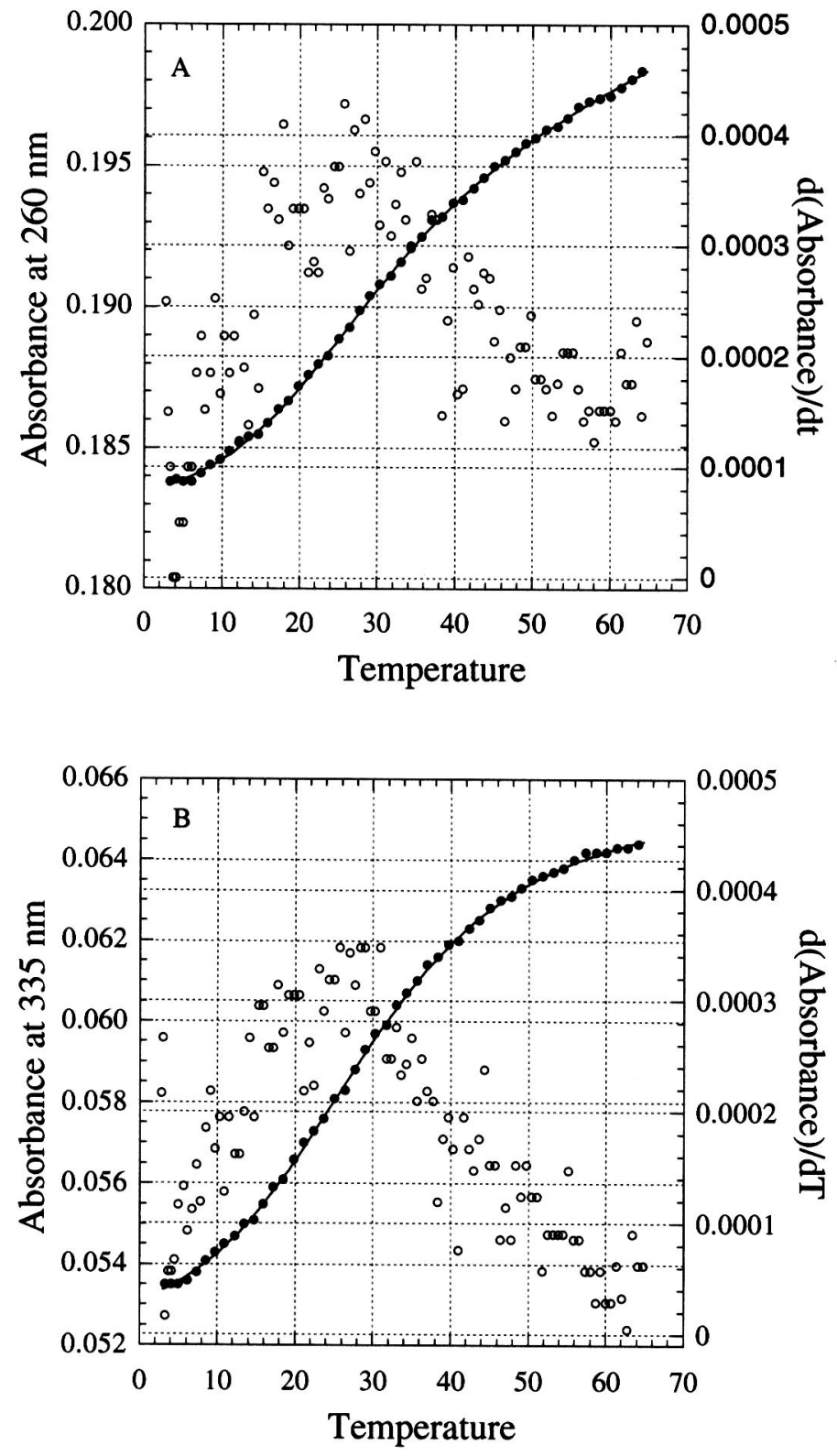

Figure 3: Thermal denaturation curves of the hpSGT hairpin at $260 \mathrm{~nm}$ (A) and $335 \mathrm{~nm}$ (B). Concentration $1.1 \mu \mathrm{M}$ of oligonucleotide, other conditions as in Figure 2. 
The formation enthalpy value derived for G.G, T $\cdot \mathrm{T}$ base pair formation in ps $\mathrm{dG}(\mathrm{GT})_{4} \mathrm{G}$ (mean value of $-13.5 \mathrm{~kJ} \mathrm{~mol}^{-1}$ ) compared well to values typical for other base pairs in various ps double helices. The values are somewhat lower than those for ps double helices with mixed A.T, G.C pairing (-14 to $-16 \mathrm{~kJ}$ mol-1 per base pair on the average), which exhibit a strong dependence on the nucleotide sequence due to an unfavorable contribution of $\mathrm{A} \cdot \mathrm{T} / \mathrm{G} \cdot \mathrm{C}$ boundaries (14). It is to be noted, however, that the $\Delta \mathrm{H}$ also depends on the nucleotide sequence even in the ps helices consisting of only $\mathrm{A} \cdot \mathrm{T}$ pairs. The $\Delta \mathrm{H}$ of $10 \mathrm{bp} \mathrm{A}$. T-pair hairpins 3'$\mathrm{d}(\mathrm{T})_{10} \mathrm{C}_{4} \mathrm{~d}(\mathrm{~A})_{10^{-3^{\prime}}}$ and $3^{\prime}-\mathrm{d}(\mathrm{T})_{10} \mathrm{G}_{4} \mathrm{~d}(\mathrm{~A})_{10^{-3^{\prime}}}$ were -198 and $-190 \mathrm{~kJ} \mathrm{~mol}^{-1}$ respectively (17), while, those of $3^{\prime}-\mathrm{d}(\mathrm{TA})_{5} \mathrm{C}_{4}(\mathrm{TA})_{5}-^{\prime}$ and $3^{\prime}-\mathrm{d}(\mathrm{TA})_{5} \mathrm{~T}_{4}(\mathrm{TA})_{5}-3^{\prime}$ were $132 \pm 10$ and $-137 \pm 10 \mathrm{~kJ} \mathrm{~mol}^{-1}$, respectively, (28). Thus, the stability of the ps $\mathrm{dG}(\mathrm{GT})_{4} \mathrm{G}$ double helix is quite close to that of a ps helix composed of alternating A - T pairs, but it is notably lower than of molecules with homo A - T pairs. A similar specific enthalpy was found in the case of $\mathrm{G} \cdot \mathrm{G}, \mathrm{A} \cdot \mathrm{T}$ containing ps hairpins: $3^{\prime}-\mathrm{d}(\mathrm{GT})_{3} \mathrm{~T}_{4}(\mathrm{AG})_{3} \mathrm{-}^{\prime}\left(-80.7 \mathrm{~kJ} \mathrm{~mol}^{-1}\right.$ i.e. $-13.5 \mathrm{~kJ} \mathrm{~mol}^{-1}$ per bp. $)$ and $3^{\prime}-$ $\mathrm{d}(\mathrm{GT})_{4} \mathrm{~T}_{4}(\mathrm{AG})_{4} \mathrm{-3}^{\prime}\left(-114 \mathrm{~kJ} \mathrm{~mol}^{-1},-14.25 \mathrm{~kJ} \mathrm{~mol}^{-1}\right.$ per bp) (29). For $\mathrm{G} \cdot \mathrm{G}, \mathrm{A} \cdot \mathrm{A}$ containing $\mathrm{d}(\mathrm{GA})_{15} \mathrm{ps}$ duplexes somewhat higher value for $\Delta \mathrm{H}$ was obtained in the presence of $10 \mathrm{mM} \mathrm{MgCl}_{2}:-16 \mathrm{~kJ}$ per mole bp (30).

Hence, the ps $\mathrm{dG}(\mathrm{GT})_{4} \mathrm{G}$ exhibits stability comparable to that of other ps double helices obtained at neutral $\mathrm{pH}$. Nevertheless the formation of this ps double helix is strongly favored and rather easy to observe because of the absence of competing alternative structures. We failed to detect any alternative conformation of hp-GT oligonucleotide over a wide range of its concentrations, in the presence of $\mathrm{Na}^{+}, \mathrm{Li}^{+}$, $\mathrm{K}^{+} \mathrm{Mg}^{2+}$ counterions or using different modes of sample preparation. Previously, short $\mathrm{d}(\mathrm{GT})_{\mathrm{n}}$ repeats flanked by oligoG stretches were shown to participate in parallel quadruplex formation $(7,11)$. We believe that the nucleotide context governs the observed structural polymorphism of the $\mathrm{d}(\mathrm{GT})_{\mathrm{n}}$ sequence. Very stable Gquadruplexes formed by three or more adjoining guanines at both ends of the $\mathrm{d}(\mathrm{GT})_{\mathrm{n}}$ repeats may facilitate a quadruplex formation for the internal GT region. The oligonucleotide $3^{\prime}-\mathrm{d}(\mathrm{GT})_{5}-\left(\mathrm{CH}_{2}\right)_{6}-\mathrm{d}(\mathrm{GT})_{5^{-}} 3^{\prime}$ (parGT) forms a tetraplex structure composed of two parallel oriented self-folded oligonucleotides (10). Such a tetraplex comprises layers of G-quartets and layers of thymines capable of bulging out of the structure. The CD spectra of the parGT tetraplex have some difference to those of hp-GT, such as a pronounced positive band at $260 \mathrm{~nm}$, a positive maximum at $277 \mathrm{~nm}$ and a greater amplitude of the negative band at $243 \mathrm{~nm}$. The strands of the folded parGT are shifted leaving free terminal thymines. An interstrand interaction of the terminal thymines may favor the bimolecular tetraplex formation over possible alternative structures.

\section{(C) Molecular Modeling}

The base pairing scheme chosen for T.T and G.G base pairs is depicted in Figure 4. The T.T and G.G base pairs are in trans orientation, bonded through two hydrogen bonds; N2-N3 for G.G and N3-O2 for T.T. Among the various base pairing possibilities (31) of T.T and G.G those two combinations were chosen, which gave best results in building a uniform ps helix. The helical parameters for the lowest energy structure are: $46.6^{\circ}$ twist and average rise $3.31 \AA$. The sugar pucker is $\mathrm{C} 2^{\prime}$-endo. The minimized structure features two equally sized grooves (Figure 5). Whereas the base step does not exhibit notable variations around the average value of $3.31 \AA$, the average twist value for the $5^{\prime}$-GT- $3^{\prime}$ step with $\sim 51^{\circ}$ is higher than the $5^{\prime}$-TG-3' step with $\sim 42^{\circ}$, thereby defining a dinucleotide motif for the helix. Due to the fact of the high average twist of $\sim 47^{\circ}$ and the helical axis pointing through the middle of the T.T and G.G base pairs the base stacking is less pronounced as for example in anti parallel B DNA helices (see Figure 4). Base pair overlap is higher in the GT step than in the TG step. In some of the G.G base pairs hydrogen bonds are formed between the $\mathrm{N} 2$ of $\mathrm{G}$ and the $\mathrm{O}^{\prime}$ of the adjacent sugar ring (see side view in Figure 4). 

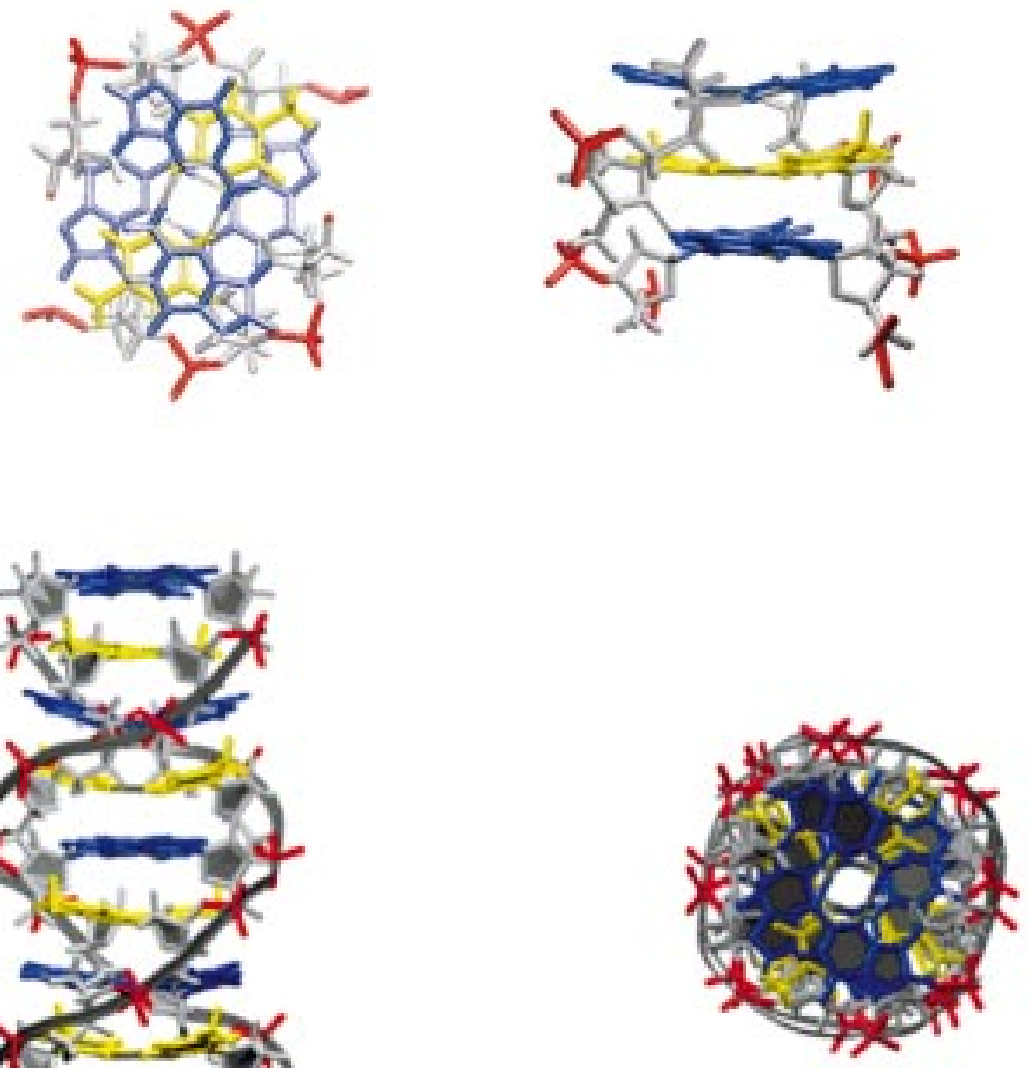

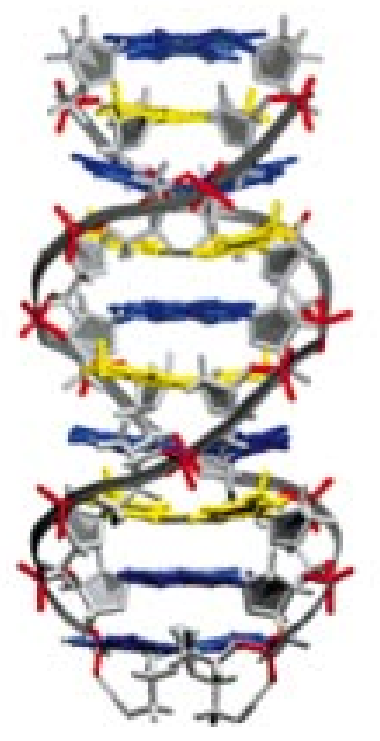

Polymorphism of $d(G T)_{n}$ Sequence

Figure 4: Top and side view of the minimized central base pairs of the ps-5'-d(GGTGTGTGT) helix. Colour coding: guanine (blue), thymine (yellow), sugar backbone (gray), phosphates (red). The $\mathrm{H}$ bonds are shown in broken gray. The H-bonding scheme of the G.G and the T.T base pairs are preserved during the minimization, with little buckle or propeller twist.
Figure 5: Side and top view of the minimized ps-5'd(GGTGTGTGT) helix (color coding as in Figure .4). Both grooves are of equal size. The ribbon following the sugar backbone reflects the higher twist between the GT step $\left(\sim 51^{\circ}\right)$ compared to the TG step $\left(\sim 42^{\circ}\right)$.

\section{Concluding Remarks}

Structurally, the simple direct repeats may produce single strand annealing or replication slippage. Being one of the most common microsatellites in eukaryotes, the GT repeat was found to be very genetically unstable, which most likely reflects DNA polymerase slippage. Interestingly, the poly $\mathrm{d}(\mathrm{GT})$ tracts in mitochondrial DNA of $S$. cerevisiae are considerably less stable than poly d(AT) tracts, involving usually deletions, whereas in the nuclear genome poly(GT) and poly(AT) tracts involve additions rather than deletions (32). These results suggest such DNA sequences may engage in organelle-specific DNA replication and/or repair processes. Various mechanisms of cell function appear to employ the broad structural flexibility of GT repeats. A zinc-dependent protein was shown to recognize structural rather than sequence-specific features of $(G T)_{n}$ stretch in the $(G T)_{n}(G A)_{n}$ containing intron of HLA-DRB allels (33). Recently, new evidence for involvement of the GT repeats in regulation of the other central processes in cells has appeared. For example, this sequence in the $5^{\prime}$-flanking region of human $\mathrm{HO}-1$ gene shows length polymorphism and modulates the level of gene transcription (34). The 5'-flanking GT repeat of rat tyrosine hydroxylase gene directs tissue specific expression during development (35).

In the present study we have demonstrated a new conformational potentiality of the GT sequence, thereby supporting the notion that in vivo, the diverse conformational potential of the $\mathrm{d}(\mathrm{GT})$ repeats may be exploited by cellular proteins for structure-related regulation of cell processes as well as for formation of structures at telomere ends. 
The study was partially supported by the Russian Foundation for Basic Research (grant N 99-04-49179), Russian Foundation "State support of the Russian leading scientific schools" (grant N 00-15-97834), NATO Linkage grant HTECH LG 971252 and the Max Planck Society.

References and Footnotes

1. R. Cox, and S.M. Mirkin, Proc. Natl. Acad. Sci. USA 94, 5237-5242 (1997).

2. R. R. Sinden, DNA structure and function, Academic Press, San Diego (1994).

3. M. Dutreix, J. Mol. Biol. 273, 105-113 (1997).

4. C.G. Gendrel, A. Boulet, M. Dutreix, Genes Dev. 14, 1261-1268 (2000).

5. S-S. Wang, and V.A. Zakian, Mol. Cell. Biol.10, 4415-4419 (1990).

6. R.J. Wellinger, A.J.Wolf, and V.A. Zakian, Cell 72, 51-60 (1993).

7. R. Giraldo, and D. Rhodes, EMBO J. 13, 2411-2420 (1994).

8. R.S. Kota, and K.W. Runge, Chromosoma 108, 278-290 (1999).

9. G. Fang, and R. T. Cech, In Blackburn., E.G.H. and Greider, C.W. (eds.), Telomeres, Cold Spring Harbor Laboratory Press, pp. 69-105 (1995).

10. O.F. Borisova, A.K. Shchyolkina, E.N Timofeev, V.L. Florentiev, FEBS Lett. 306, 140-142 (1992).

11. R. Giraldo, M. Suzuki, L. Chapman, and D. Rhodes, PNAS USA 91, 7658-7662 (1994).

12. J.D. Griffith, L. Comeau, S. Rosenfeld, R.M. Stansel, A. Bianchi, H. Moss, and T. de Lange, Cell 97, 503-514 (1999).

13. G. Weber, and S. Anderson, Biochemistry 8, 361-371 (1969).

14. A.K . Shchyolkina, O.F. Borisova, M.A. Livshits, G.E. Pozmogova, B.K. Chernov, R. Klement, and T.M. Jovin, Biochemistry 39, 10034-10044 (2000).

15. D. Rhodes, Eur. J. Biochem. 81, 91-101 (1977).

16. P. Balaggurumoorthy and K. Brahmachari, J. Biol. Chem. 269, 21858-21869 (1994)

17. N. B. Ramsing, K. Rippe, and T. M. Jovin, Biochemistry, 28, 9528-9535 (1989).

18. J. Applequist, and V. Damle, J. Am. Chem. Soc. 87, 1450-1458 (1965).

19. C.S. Tung, and E.S. Carter, CABIOS 10, 427-433 (1994).

20. D.A. Case, D.A. Pearlman, J.W. Caldwell, T.E. Cheatham III, W.S. Ross, C.L. Simmerling, T.A. Darden, K.M. Merz, R.V. Stanton, A.L. Cheng, J.J. Vincent, M.Crowley, D.M. Ferguson, R.J. Radmer, G.L. Seibel, U.C. Singh, P.K. Weiner and P.A. Kollman, AMBER 5, University of California, San Francisco (1997).

21. W. Humphrey, A. Dalke, and K. Schulten, VMD -Visual Molecular Dynamics J. Molecular Graphics 14, 33-38 (1996).

22. F.-M. Chen, Biochemistry 31, 3769-3776 (1992).

23. F. Eckstein, and K.H. Scheit, In Cantoni, G.L. and Davies, D.R., (eds.), Procedures in Nucleic Acid Research 2, Harper and Row, New York, pp. 665-679 (1971).

24. T.M. Jovin, N.Geisler, and K. Weber, Nature 269, 668-672 (1977).

25. B.A.Connoly, and P.C. Newman, Nucl. Acid Res. 17, 4957-4974 (1989).

26. O. F. Borisova, Yu. B. Golova, B. P. Gottikh, A. S. Zibrov, I. A. Il'icheva, Yu. P. Lysov, O. K. Mamayeva, B. K. Chernov, A. A. Chernyi, A. K. Shchyolkina, and V. L. Florentiev, J. Biomol. Struct. Dynam. 8, 1187-1210 (1991).

27. A.L. Williams, Jr., C. Cheong, I. Tinoco, Jr., L.B. Clark, Nucl. Acid Res. 14, 6649-6659 (1986).

28. M.W. Germann, B. W. Kalish, R. T. Pon, and J. H. van de Sande, Biochemistry 29, 9426-9432 (1990).

29. M.W. Germann, B. W. Kalish, and J. H. van de Sande, Biochemistry 37, 12962-12970 (1998).

30. K. Rippe, V. Fritsch, E. Westhof, and T.M. Jovin, EMBO J. 11, 3777-3786 (1992).

31. P. Hobza, and C. Sandorfy, J. Am. Chem. Soc. 109, 1302-1307 (1987).

32. E.A. Sia, C.A. Butler, M. Dominska, P.Greenwell, T.D. Fox, T.D. Petes, Proc. Natl. Acad. Sci. USA 97, 250-255 (2000).

33. W. Maueler, G. Bassili, C. Epplen, H.G. Keyl, J.T. Epplen, Chromosome Res. 7, 163-166 (1999).

34. N. Yamada, M. Yamaya, S. Okinaga, K. Nakayama, K.Sezawa, S. Shibahara, H. Sasaki, Am. J. Hum. Genet. 66,187-195 (2000).

35. J.J. Schimmel, L. Crews, S. Roffler-Tarlov, D.M. Chikaraishi, Brain. Res. Mol. Brain Res. 74, $1-14(2000)$.

Date Received: November 13, 2000

\section{Comunicated by the Editor Valery Ivanov}

